Research article

Open Access

\title{
Therapeutic efficacy of intra-articular adrenomedullin injection in antigen-induced arthritis in rabbits
}

\author{
Toshiyuki Okura ${ }^{1}$, Kousuke Marutsuka², Hiroaki Hamada ${ }^{1}$, Tomohisa Sekimoto $^{1}$, \\ Tsuyoshi Fukushima ${ }^{3}$, Yujiro Asada ${ }^{2}$, Kazuo Kitamura ${ }^{4}$ and Etsuo Chosa ${ }^{1}$
}

\author{
1Division of Orthopedic Surgery, Department of Medicine of Sensory and Motor Organs, Faculty of Medicine, University of Miyazaki, 5200 Kihara, \\ Kiyotake, Miyazaki 889-1692, Japan \\ 2Section of Pathophysiology, Department of Pathology, Faculty of Medicine, University of Miyazaki, 5200 Kihara, Kiyotake, Miyazaki 889-1692, Japan \\ ${ }^{3}$ Section of Oncopathology and Regenerative Biology, Department of Pathology, Faculty of Medicine, University of Miyazaki, 5200 Kihara, Kiyotake, \\ Miyazaki 889-1692, Japan \\ ${ }^{4}$ Division of Circulatory and Body Fluid Regulation, Department of Internal Medicine, Faculty of Medicine, University of Miyazaki, 5200 Kihara, Kiyotake, \\ Miyazaki 889-1692, Japan \\ Corresponding author: Etsuo Chosa, chosa@med.miyazaki-u.ac.jp
}

Received: 12 Jun 2008 Revisions requested: 17 Jul 2008 Revisions received: 15 Oct 2008 Accepted: 13 Nov 2008 Published: 13 Nov 2008

Arthritis Research \& Therapy 2008, 10:R133 (doi:10.1186/ar2550)

This article is online at: http://arthritis-research.com/content/10/6/R133

(c) 2008 Okura et al.; licensee BioMed Central Ltd.

This is an open access article distributed under the terms of the Creative Commons Attribution License (http://creativecommons.org/licenses/by/2.0), which permits unrestricted use, distribution, and reproduction in any medium, provided the original work is properly cited.

\begin{abstract}
Introduction Adrenomedullin is a potent vasodilatory and hypotensive peptide as well as an endogenous immunomodulatory factor with predominantly anti-inflammatory effects. The purpose of the present study was to evaluate the therapeutic effects of adrenomedullin in rabbits with antigeninduced arthritis, an experimental model of rheumatoid arthritis.

Methods Following the induction of arthritis in both knee joints by ovalbumin injection into the joint spaces of pre-immunized rabbits, increasing daily doses of adrenomedullin were injected into the knee joint spaces or saline was injected into the contralateral knee joint spaces as the control. For time-course experiments, adrenomedullin and saline were injected into the knee joint spaces daily for 7 days and 20 days. The degree of joint swelling and the histological change in the knee joints injected with adrenomedullin were compared with the control knee joints. Histological evaluation of the infrapatellar fat pads and synovial tissue was performed. TNF $\alpha$, IL-6, vascular endothelial growth factor and transforming growth factor-beta
\end{abstract}

mRNA levels in the synovial tissue were measured using realtime quantitative PCR.

Results Daily injections of adrenomedullin into the knee joint spaces of rabbits with antigen-induced arthritis decreased joint swelling. Histological examination revealed that adrenomedullin reduced edematous changes and the infiltration of inflammatory cells in the synovial tissues. Analysis of mRNA levels showed that adrenomedullin significantly reduced TNF $\alpha$ mRNA expression by $21 \%$ to $49 \%$ in a dose-dependent manner, and dose-dependently increased IL- 6 mRNA expression by $45 \%$ to $121 \%$.

Conclusions These results suggest that daily injections of adrenomedullin into the knee joint spaces of rabbits with antigen-induced arthritis ameliorated the inflammatory response in arthritic joints. Adrenomedullin may thus be useful as a treatment for rheumatoid arthritis; however, the effect of adrenomedullin on IL-6 production in the synovial tissue may be an undesirable adverse effect in rheumatoid arthritis therapy.

\section{Introduction}

Rheumatoid arthritis (RA) is a chronic and systemic inflammatory disorder affecting multiple joints. The causes of RA are not fully understood, and the treatment has not been completely established. The cytokine network, consisting of many inflammatory cytokines, mediates the chronic inflammatory process, including that in RA. The balance between proinflammatory cytokines and anti-inflammatory cytokines is important in determining the grade and extent of inflammation. Considerable progress has been reported in the use of biological agents that mediate the pathogenesis of RA, especially antibodies to TNF $\alpha$ and soluble TNF $\alpha$ receptors $[1,2]$. 
Adrenomedullin (AM) is a 52-amino-acid peptide, which was originally isolated from extracts of human pheochromocytoma using elevated platelet cAMP activity as an indicator [3]. Besides its potent vasodilatory and hypotensive effects, $A M$ is also known to have other multiple regulatory functions. Several studies have suggested that AM acts as an endogenous immunomodulatory factor, with predominantly anti-inflammatory effects. It has been reported that AM reduces the secretion of TNF $\alpha$ from activated macrophages [4-6]. In addition, AM has been shown to ameliorate colitis in murine models $[7,8]$. Moreover, AM was reported to abrogate arthritis in a murine model via an inhibitory effect on the Thelper type 1driven autoimmune and inflammatory responses [9].

We and other investigators have reported that elevated AM levels are found in plasma, joint fluid, and the synovium in RA $[10,11]$. From the observations of the anti-inflammatory effects of AM, it is speculated that the body responds to an inflammatory condition and attempts to ameliorate arthritis by increasing the secretion of AM.

The aim of the present study was to investigate the therapeutic effects of AM in an animal model of RA in vivo. We used rabbits with antigen-induced arthritis (AIA), an experimental model of RA [12,13]. We showed that daily injections of AM into the knee joint spaces of rabbits with AIA decreased joint swelling. Histological examination revealed that AM reduced edematous changes and the infiltration of inflammatory cells in the synovial tissues. Analysis of mRNA levels in the synovial tissue demonstrated that $A M$ significantly reduced the $T N F \alpha$ mRNA level, but increased the IL-6 mRNA level. These results suggest that, although AM ameliorated joint pathology in the rabbit AIA model, the effect of AM on IL-6 production might be an adverse effect in RA therapy.

\section{Materials and methods Animals}

Female Japanese white rabbits (Kyudo Co., Ltd, Saga, Japan) weighing 3.1 to $3.5 \mathrm{~kg}$ were used in the study. The rabbits were housed in a temperature-controlled and humidity-controlled room and were maintained on standard pellet chow and tap water. All experiments were performed under the regulations of the Animal Research Committee of Miyazaki University.

\section{Induction of antigen-induced arthritis}

The AIA rabbit model was developed as described by Consden and colleagues [13]. Briefly, rabbits were anesthetized by an intravenous injection of pentobarbital sodium and were immunized by $1.2 \mathrm{ml}$ intradermal injections of $6 \mathrm{mg} / \mathrm{ml}$ ovalbumin (Sigma-Aldrich, St Louis, MO, USA) in saline emulsified with an equal volume of TiterMax Gold (TiterMax, Norcross, GA, USA). The rabbits were re-immunized in the same manner 30 days later. Seven days after the second immunization, the rabbits underwent skin testing following a $0.1 \mathrm{ml}$ intra- dermal injection of a solution of $200 \mu \mathrm{g} / \mathrm{ml}$ ovalbumin in saline. Animals exhibiting a welt of $13 \mathrm{~mm}$ or greater after 24 hours were confirmed as 'immunized'. Twelve days after the second immunization, the 'immunized' rabbits were anesthetized and arthritis was induced by $0.5 \mathrm{ml}$ bilateral knee intra-articular injections of a solution of $20 \mathrm{mg} / \mathrm{ml}$ ovalbumin in saline.

\section{Treatment protocol}

Twenty-four hours after arthritis induction, the rabbits were anesthetized and different doses of AM ( $1 \mathrm{ng}$ to $3 \mu \mathrm{g}$; Peptide Institute Inc., Osaka, Japan) dissolved in $0.3 \mathrm{ml}$ saline were injected into the knee joint spaces or $0.3 \mathrm{ml}$ saline was injected into the contralateral knee joint spaces as controls. For time-course experiments, AM and saline were injected into the knee joint spaces daily for 7 days and 20 days. The rabbits were sacrificed on day 8 ( $n=5$ in each group) and day 21 ( $n$ $=3$ in each group).

\section{Measurement of adrenomedullin in plasma}

To evaluate the effect of intra-articular injection of $A M$ on the blood concentration, whole-blood samples (total $1 \mathrm{ml}$ ) were taken from a peripheral artery in the rabbit ear using a 22gauge needle before and 15, 30, 60 and 120 minutes after intra-articular injection of $3 \mu \mathrm{g} \mathrm{AM}$. Blood samples were transferred into tubes containing $1 \mathrm{mg} / \mathrm{ml}$ disodium ethylenediamine tetraacetic acid and 500 kallikrein inhibitory units $/ \mathrm{ml}$ aprotinin, and were centrifuged for 15 minutes at $1670 \mathrm{~g}$. The plasma was stored at $-30^{\circ} \mathrm{C}$ until assayed. Plasma AM concentration was measured using an immunoenzymometric assay kit [14].

\section{Joint swelling}

To evaluate the grade of arthritis/inflammation, joint swelling was assessed by measuring the maximum diameter of the swollen joint using calipers. The swelling was compared with that at the same level on the contralateral knee, treated with saline.

\section{Histological evaluation}

For histological evaluation, rabbits were given an overdose of pentobarbital 8 days and 21 days after arthritis induction. The infrapatellar fat pads were harvested from dissected knees and were cut longitudinally, perpendicular to the patella ligament in the middle of the infrapatellar fat pad. The tissues were fixed in 10\% buffered formaldehyde and embedded in paraffin wax, and sections $3 \mu \mathrm{m}$ thick were obtained. The specimens were stained with $H$ \& E and Mallory-Azan stains. The area of the infrapatellar fat pad was measured using AxioVision software (release 4.3; ZEISS, Oberkochen, Germany). Inflammatory cells, including lymphocytes and plasma cells, were counted in the superficial and deep portions of the infrapatellar fat pads (three fields under $\times 200$ magnification in each portion) in $\mathrm{H}$ \& E-stained specimens. The inflammatory cell count was performed by two independent observers. 
To measure the collagen volume, the images of sections with Mallory-Azan stain were projected onto a color imaging analysis system (Mac SCOPE version 2.3.2; Mitani, Fukui, Japan). In each section, 10 separate sites were analyzed at $\times 40$ magnification. The collagen volume fraction was obtained by calculating the mean ratio of connective tissue to the total tissue area.

\section{Measurement of cytokine mRNA}

Total RNA was extracted from the infrapatellar fat pad with TRIzol reagent (Invitrogen, Carlsbad, CA, USA) according to the manufacturer's protocol and was then reverse-transcribed into cDNA with the SuperScript First-Strand Synthesis System for RT-PCR kit (Invitrogen). To measure rabbit TNF $\alpha$, IL-6, vascular endothelial growth factor (VEGF), transforming growth factor beta (TGF $\beta$ ), and $\beta$-actin mRNA levels, we used the quantitative RT-PCR method of real-time quantitative PCR.

Table 1 presents the sequences of the primers for TNF $\alpha$ [GenBank:M12845], IL-6 [GenBank: AF169176], VEGF [GenBank:AY196796], TGF $\beta$ [GenBank:AB020217], and $\beta$-actin [GenBank:AF309819] [15]. PCR was performed in a LightCycler (Roche, Basel, Switzerland) using the SYBR Premix Ex Taq kit (Takara Bio, Shiga, Japan) according to the manufacturer's instructions. We obtained data from three independent experiments. The mRNA levels were compared after they had been normalized relative to those of $\beta$-actin.

\section{Measurement of TNF $\alpha$ and IL-6}

Protein extracts were isolated by homogenization of infrapatellar fat pads (50 mg tissue $/ \mathrm{ml}$ ) in $50 \mathrm{mmol} / \mathrm{l}$ Tris $-\mathrm{HCl}, \mathrm{pH} 7.4$, with $0.5 \mathrm{mmol} / \mathrm{l}$ dithiothreitol, and $10 \mu \mathrm{l} / \mathrm{ml}$ protease inhibitor cocktail (Sigma-Aldrich). The samples were centrifuged at $30,000 \times g$ for 20 minutes and stored at $-30^{\circ} \mathrm{C}$ until assayed. TNF $\alpha$ and IL- 6 levels in the protein extracts were measured using ELISA kits for human TNF $\alpha$ and IL-6 (R\&D Systems, Minneapolis, MN, USA) according to Zagariya and colleagues [16]. The TNF $\alpha$ level in the protein extracts was also measured by SDS-PAGE and western blotting using Armenian hamster anti-mouse TNF $\alpha$ monoclonal antibody (Santa Cruz Biotechnology, Santa Cruz, CA, USA). We could not, however, obtain worthwhile data by these methods (data not shown). It was considered that these ELISA kits and the anti-mouse TNF $\alpha$ monoclonal antibody may not cross-react with rabbit IL- 6 and TNF $\alpha$, or that TNF $\alpha$ and IL- 6 levels in the protein extracts were lower than the detection limits of these assays.

\section{Statistical analysis}

In all experiments, we compared values for AM-treated knees with control knees from the same animal. All data are expressed as the mean \pm standard error. The differences were analyzed using the Mann-Whitney $U$ test. $P<0.05$ was considered statistically significant.

\section{Results}

\section{Adrenomedullin concentration in plasma}

We measured the plasma AM concentration before and 15 , 30,60 and 120 minutes after intra-articular injection of $3 \mu \mathrm{g}$ AM $(n=6)$. No significant change, however, was observed in the plasma concentration of AM (Figure 1). The intra-articular injection of $A M$ did not therefore increase the level of $A M$ in plasma.

\section{Joint swelling}

To evaluate the anti-inflammatory effect of $A M$ on arthritis, we used calipers to measure joint swelling in AM-treated knees and compared the swelling with that at the same level on the contralateral knees, treated with saline. In rabbits with AIA treated with daily injections of AM or saline into the knee joint spaces for 7 days, $3 \mu \mathrm{g}$ AM significantly reduced joint swelling

Table 1

Primers for real-time PCR

\begin{tabular}{|c|c|c|c|}
\hline Gene & GenBank accession number & Product (base pairs) & $\begin{array}{l}\text { Oligonucleotide sequences (forward and reverse } \\
\text { primers) }\end{array}$ \\
\hline \multirow[t]{2}{*}{ TNF $\alpha^{a}$} & [GenBank:M12845] & 252 & AGCCCACGTAGTAGCAAACCC \\
\hline & & & TTGATGGCAGAGAGGAGGTTGA \\
\hline \multirow[t]{2}{*}{ IL-6 } & [GenBank:AF169176] & 93 & CCGGCGGTGAATAATGAGAC \\
\hline & & & CCTGAACTTGGCCTGAAGGTG \\
\hline \multirow[t]{2}{*}{ Vascular endothelial growth factor } & [GenBank:AY196796] & 91 & AATGATGAAAGCCTGGAGTGTGTG \\
\hline & & & CTATGTGCTGGCCCTGGTGA \\
\hline \multirow[t]{2}{*}{ Transforming growth factor beta } & [GenBank:AB020217] & 136 & AAGGACCTGGGCTGGAAGTG \\
\hline & & & CCGGGTTGTGCTGGTTGTA \\
\hline \multirow[t]{2}{*}{$\beta$-Actin } & [GenBank:AF309819] & 183 & CCATGTACGTGGCCATCCAG \\
\hline & & & TCTTCATGAGGTAGTCGGTCAGGTC \\
\hline
\end{tabular}

aPrimer source was Reno and colleagues [15]. 
Figure 1

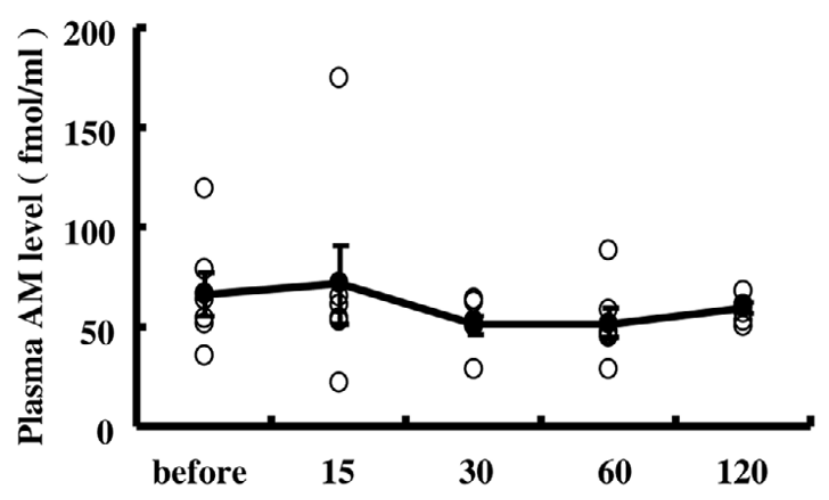

Time after intra-articular injection of $3 \mu \mathrm{g}$ AM ( min )

Sequential concentrations of plasma adrenomedullin following intra-articular adrenomedullin injection in rabbits with antigeninduced arthritis. Whole-blood samples (total $1 \mathrm{ml}$ ) were taken from a peripheral artery in the rabbit ear using a 22-gauge needle before and $15,30,60$ and 120 minutes after intra-articular injection of $3 \mu \mathrm{g}$ adrenomedullin (AM). The plasma AM concentration was measured using an immunoenzymometric assay kit $(n=6)$. White circles, plasma AM levels in rabbits; black circles, average plasma AM levels at each time point after intra-articular injection of $3 \mu \mathrm{g}$ AM. Data expressed as the mean \pm standard error of the mean.

compared with contralateral knees after day 5. No significant decrease in joint swelling was observed, however, in knees treated with $<0.1 \mu \mathrm{g} \mathrm{AM} \mathrm{(Figures} 2 \mathrm{a}$ and 3 ). In rabbits with AIA treated for 20 days with daily injections of AM or saline into the knee joint spaces, $0.1 \mu \mathrm{g}$ and $3 \mu \mathrm{g}$ AM showed a tendency to reduce joint swelling throughout the experiment and significantly decreased joint swelling on days 12 and 16 and on days 8, 12 and 16, respectively, compared with contralateral knees (Figure 2b). Daily intra-articular injections of 1 ng and $0.01 \mu \mathrm{g} \mathrm{AM,} \mathrm{however,} \mathrm{did} \mathrm{not} \mathrm{ameliorate} \mathrm{joint} \mathrm{swelling}$ (data not shown).

\section{Histological findings}

To evaluate the effect of AM on synovial tissue and intra-articular tissue in the inflamed joints, we examined the infrapatellar fat pads by histology. The infrapatellar fat pads harvested from control knees on day 8 showed a dense inflammatory reaction, including edematous changes in the synovial interstitium, intracellular edema in the infrapatellar fat pads, hyperplasia of synovial surface cells and widespread infiltration of inflammatory cells in the infrapatellar fat pads (Figure 4d,e,f). In contrast, these inflammatory reactions were suppressed in the knees treated with AM for 7 days. In particular, edematous changes in the synovial interstitium, intracellular edema in the infrapatellar fat pads and infiltration of inflammatory cells in the deep portion of the infrapatellar fat pads were significantly reduced (Figure 4a,b,c). The infrapatellar fat pads harvested from control knees on day 21 also showed a severe inflammatory reaction. Edematous changes in the synovial interstitium, hyperplasia of synovial surface cells and widespread infiltra-
Figure 2
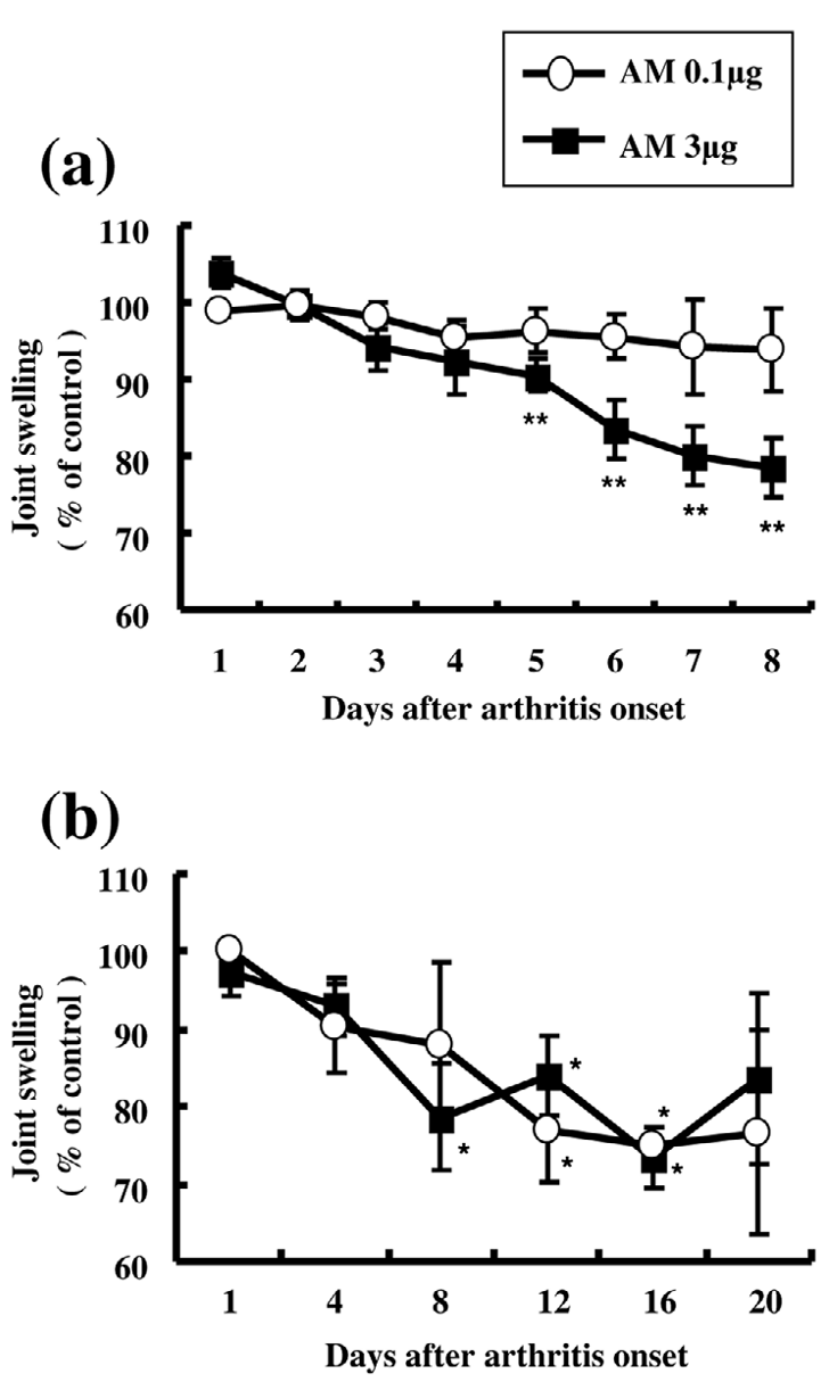

Adrenomedullin reduced joint swelling in rabbits with antigeninduced arthritis. Rabbits with antigen-induced arthritis (AIA) were treated with daily injections of adrenomedullin (AM) or saline (control) into the knee joint spaces beginning 24 hours after arthritis onset. Joint swelling was defined as the increase in knee diameter from normal and was compared with that at the same level on the contralateral knee, treated with saline. (a) Joint swelling progress in rabbits with AIA treated with daily intra-articular injections of AM or saline for 7 days ( $n$ $=5$ in each group). Daily intra-articular injections of $3 \mu \mathrm{g} \mathrm{AM} \mathrm{signifi-}$ cantly decreased joint swelling compared with contralateral knees after day 5. No significant decrease in joint swelling was observed in knees treated with $<0.1 \mu \mathrm{g}$ AM. (b) Joint swelling progress in rabbits with AIA treated with daily intra-articular injections of AM or saline for 20 days ( $n$ $=3$ in each group). Daily intra-articular injections of $0.1 \mu \mathrm{g}$ and $3 \mu \mathrm{g}$ AM showed a tendency to reduce joint swelling throughout the experiment, and significantly decreased joint swelling on days 12 and 16 and on days 8,12 and 16 , respectively, compared with contralateral control knees. Daily intra-articular injections of $1 \mathrm{ng}$ and $0.01 \mu \mathrm{g} \mathrm{AM}$ did not ameliorate joint swelling throughout the experiments (data not shown). Data expressed as the mean \pm standard error of the mean. ${ }^{\star} P<0.05$ and ${ }^{\star \star} P<0.01$, compared with contralateral knees. 
Figure 3

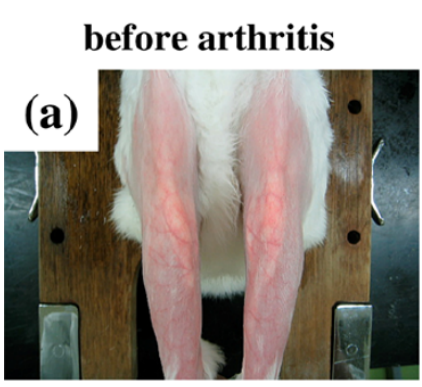

day 8
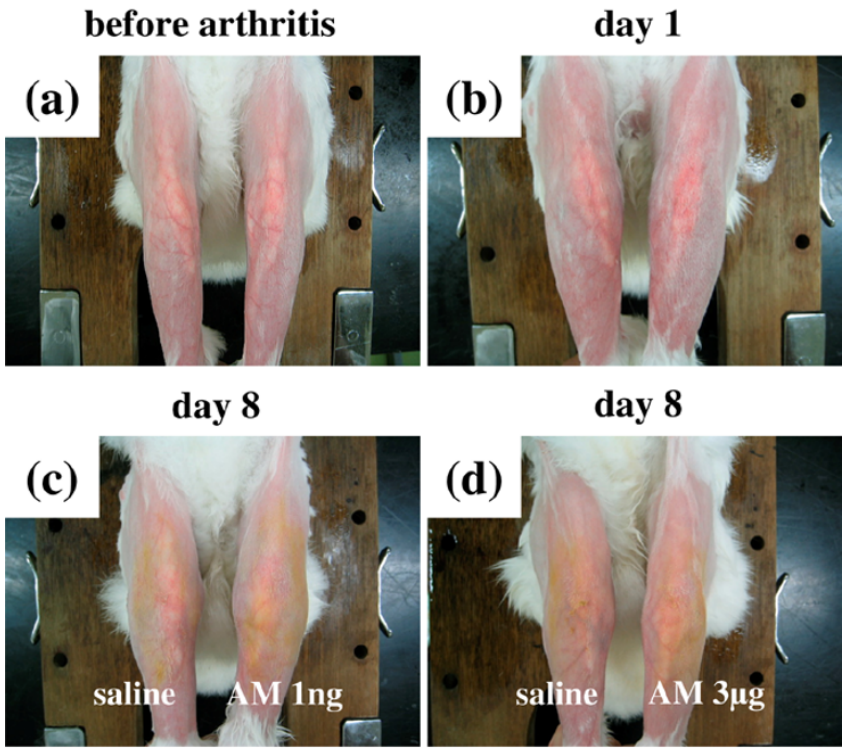

day 8

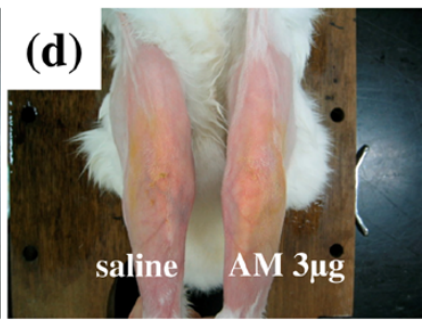

Macroscopic pathology of joint swelling in rabbits with antigeninduced arthritis. (a) Photograph taken before arthritis onset. (b) Photograph taken 24 hours after arthritis onset. (c) The left knee of the rabbit with antigen-induced arthritis (AIA) was treated with daily intraarticular injections of $1 \mathrm{ng}$ adrenomedullin (AM) for 7 days and the right knee was treated with daily intra-articular injections of saline for 7 days. Photograph taken 8 days after arthritis onset. (d) The left knee of the rabbit with AIA was treated with daily intra-articular injections of $3 \mu \mathrm{g}$ AM for 7 days and the right knee was treated with daily intra-articular injections of saline for 7 days. Photograph taken 8 days after arthritis onset.

tion of inflammatory cells throughout the infrapatellar fat pads were observed (Figure 5d,e,f). In the knees treated with AM for 20 days, these inflammatory reactions were ameliorated. AM treatment significantly suppressed infiltration of inflammatory cells in the deep portion of the infrapatellar fat pads (Figure $5 a, b, c)$.

The total number of inflammatory cells that infiltrated the infrapatellar fat pad was significantly reduced by $26 \%$ at $0.1 \mu \mathrm{g}$ AM on day 21 (Figure 6a). Daily intra-articular injections of 3 $\mu \mathrm{g}$ AM significantly suppressed the total number of inflammatory cells infiltrating the infrapatellar fat pad by $38 \%$ and $23 \%$ at day 8 and day 21, respectively, and suppressed the infiltration of inflammatory cells in the deep portion of the infrapatellar fat pad by $49 \%$ and $54 \%$ at day 8 and day 21 , respectively, compared with the controls (Figure 6).

To examine the effect of $\mathrm{AM}$ on tissue edema, we measured the total area of the infrapatellar fat pad using software. Daily intra-articular injections of $3 \mu \mathrm{g} \mathrm{AM}$ significantly decreased the total area of the infrapatellar fat pad by $15 \%$ and $20 \%$ at day 8 and day 21, respectively, compared with the controls (Figure 7).
Figure 4

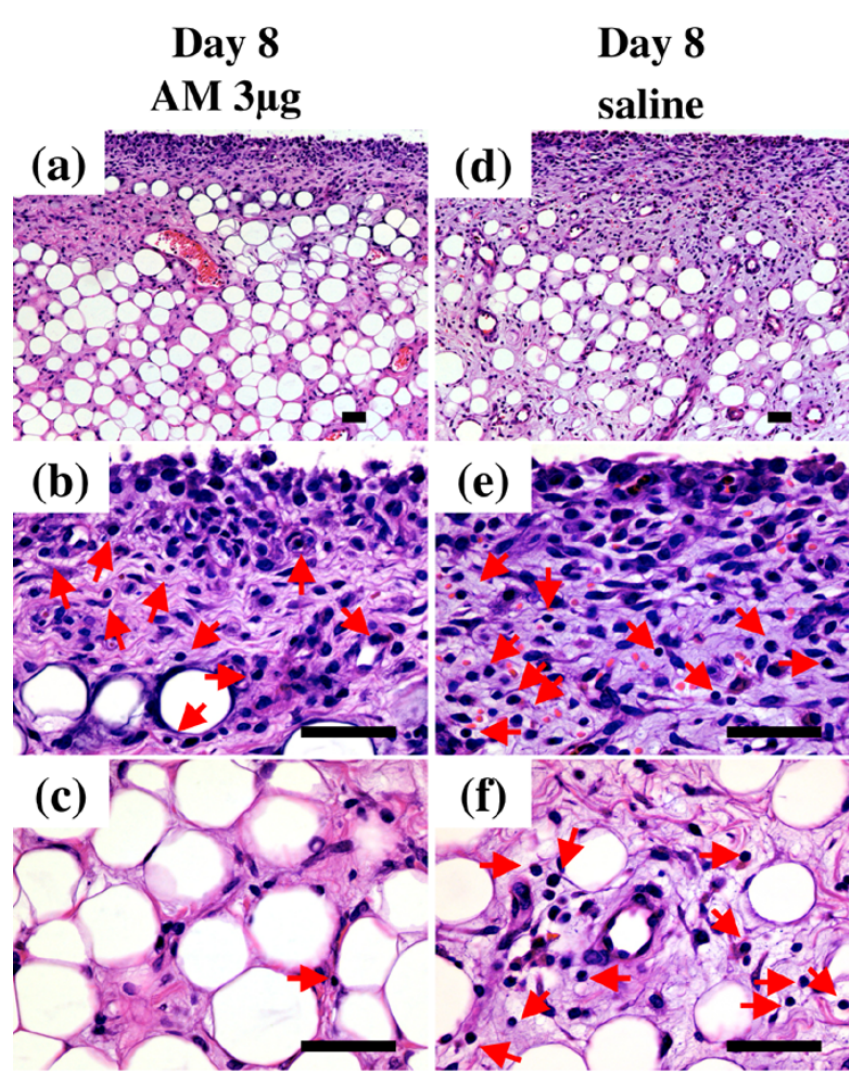

Histological analysis of infrapatellar fat pad harvested from rabbit knees $\mathbf{8}$ days after arthritis onset. Rabbits with antigen-induced arthritis (AIA) were treated with daily injections of adrenomedullin (AM) or saline (control) into the knee joint spaces for 7 days. The infrapatellar fat pads were harvested from rabbit knees 8 days after arthritis onset. Tissues were sectioned longitudinally perpendicular to the patella ligament in the middle of the tissue, and were stained with $\mathrm{H}$ \& E. (a), (b), (c) AIA rabbit knee was treated with daily intra-articular injections of 3 $\mu \mathrm{g}$ AM for 7 days. (a) Low-magnification image $(\times 100)$. (b), (c) Highmagnification images $(\times 400)$ of the superficial portion and the deep portion of (a), respectively. (d), (e), (f) The contralateral knee of (a), (b) and (c) was treated with daily intra-articular injections of saline for 7 days. (d) Low-magnification image $(\times 100)$. (e), (f) High-magnification images $(\times 400)$ of the superficial portion and the deep portion of $(d)$, respectively. Arrows indicate inflammatory cells. Bar $=50 \mu \mathrm{m}$.

To observe the effect of AM on fibrosis of the infrapatellar fat pads harvested on day 21 , we examined the collagen volume ratio of the infrapatellar fat pad histologically using Mallory-Azan staining. The collagen volume ratio was significantly increased in AM-treated knees by $39 \%$ and $31 \%$ at $0.1 \mu \mathrm{g}$ and $3 \mu \mathrm{g} \mathrm{AM}$, respectively, compared with control knees (Figures 8 and 9). The effects of AM on these pathological tissue changes, however, were not observed in knees treated with low-dose AM.

\section{Cytokines}

To elucidate the mechanism of the anti-inflammatory effects of $A M$ in inflamed joints, we investigated the effect of $A M$ on cytokine mRNA expression linked to AIA. Treatment with AM 
Figure 5

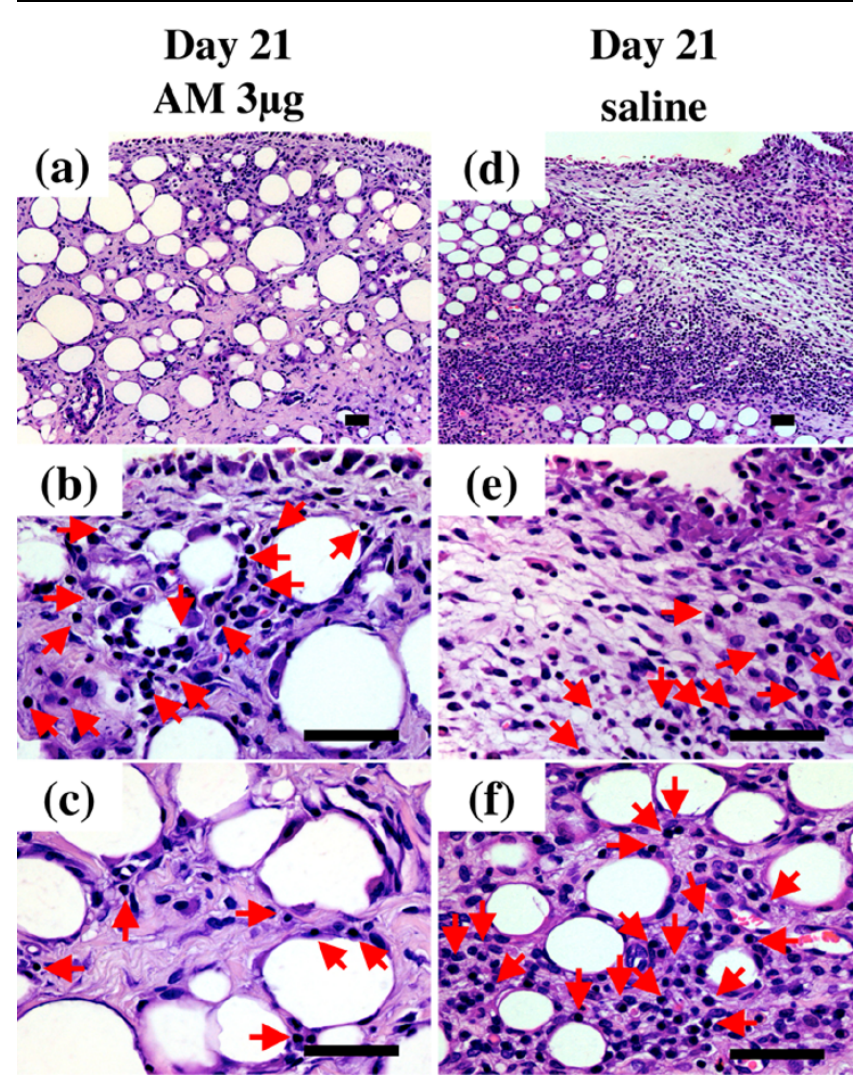

Histological analysis of infrapatellar fat pad harvested from rabbit knees 21 days after arthritis onset. Rabbits with antigen-induced arthritis (AIA) were treated with daily injections of adrenomedullin (AM) or saline (control) into the knee joint spaces for 20 days. The infrapatellar fat pads were harvested from rabbit knees 21 days after arthritis onset. The tissues were sectioned longitudinally perpendicular to the patella ligament in the middle of the tissue, and were stained with $\mathrm{H}$ \& E. (a), (b), (c) AIA rabbit knee was treated with daily intra-articular injections of $3 \mu \mathrm{g} A M$ for 20 days. (a) Low-magnification image $(\times 100)$. (b), (c) High-magnification images $(\times 400)$ of the superficial portion and the deep portion of (a), respectively. (d), (e), (f) The contralateral knee of (a), (b) and (c) was treated with daily intra-articular injections of saline for 20 days. (d) Low-magnification image (x100). (e), (f) Highmagnification images $(\times 400)$ of the superficial portion and the deep portion of (d), respectively. Arrows indicate inflammatory cells. Bar $=$ $50 \mu \mathrm{m}$.

reduced TNF $\alpha$ mRNA expression in a dose-dependent manner. Daily intra-articular injections of $3 \mu \mathrm{g} \mathrm{AM}$ significantly suppressed the TNF $\alpha$ mRNA level by $21 \%$ and $49 \%$ at day 8 and day 21, respectively, compared with controls (Figure 10a). In contrast, AM dose-dependently increased IL-6 mRNA expression. Daily intra-articular injections of $3 \mu \mathrm{g}$ AM significantly increased the IL- 6 mRNA level by $45 \%$ and $121 \%$ at day 8 and day 21, respectively, compared with controls (Figure 10b). Although the VEGF mRNA level was suppressed by $10 \%$ at 3 $\mu \mathrm{g}$ AM on day 8, we did not observe a dose-dependent effect of AM on VEGF mRNA expression (Figure 10d). AM treatment did not significantly alter the TGF $\beta$ mRNA level (Figure 10c).
Figure 6
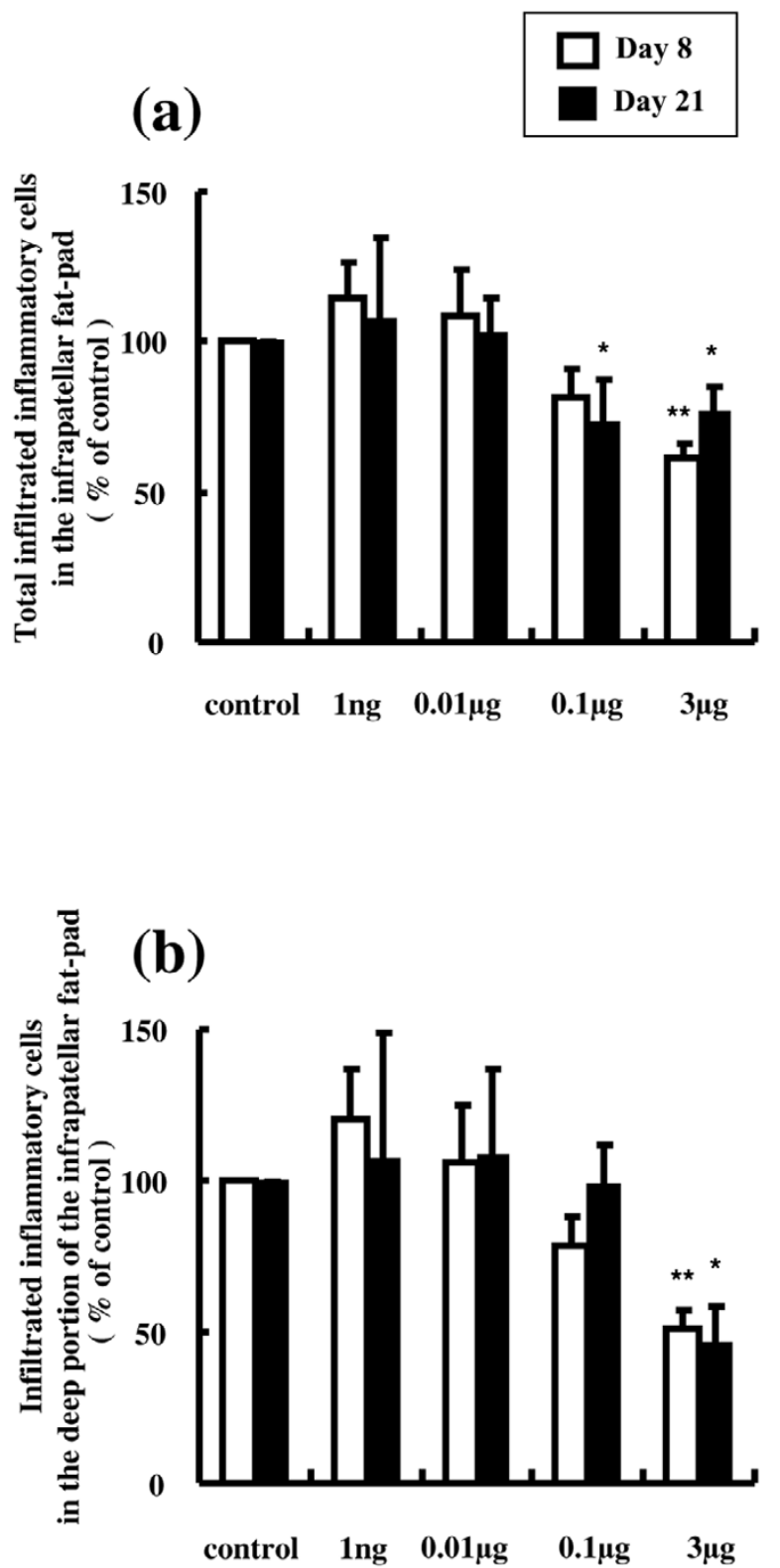

Effect of adrenomedullin on the infiltration of inflammatory cells in the infrapatellar fat pad. (a) Total number of inflammatory cells that infiltrated the infrapatellar fat pad (three sites in the superficial portion, three sites in the deep portion). The total number of inflammatory cells that infiltrated the infrapatellar fat pad was significantly reduced by $26 \%$ with daily intra-articular injections of $0.1 \mu \mathrm{g}$ adrenomedullin (AM) on day 21. Daily intra-articular injections of $3 \mu \mathrm{g}$ AM significantly suppressed the total number of inflammatory cells by $38 \%$ and $23 \%$ at day 8 and day 21, respectively. (b) Number of inflammatory cells that infiltrated the deep portion of the infrapatellar fat pad (three sites). Daily intra-articular injections of $3 \mu \mathrm{g} \mathrm{AM}$ significantly suppressed the infiltration of inflammatory cells in the deep portion of the infrapatellar fat pad by $49 \%$ and $54 \%$ at day 8 and day 21 , respectively. Open and closed columns represent the data at day 8 ( $n=5$ in each group) and at day 21 ( $n=3$ in each group), respectively. Data expressed as the mean \pm standard error of the mean. ${ }^{*} P<0.05$ and ${ }^{* *} P<0.01$, compared with contralateral knees. 
Figure 7

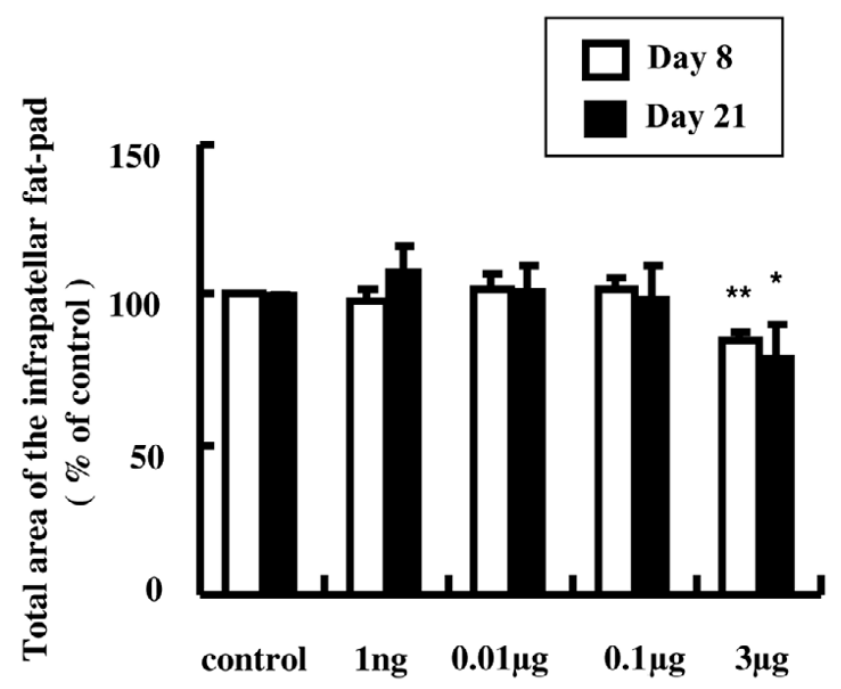

Effect of adrenomedullin on the total area of the infrapatellar fat pad. The infrapatellar fat pads were sectioned longitudinally perpendicular to the patella ligament in the middle of the tissue, and the total tissue area was determined using software. Daily intra-articular injections of $3 \mu \mathrm{g}$ adrenomedullin (AM) significantly reduced the total tissue area by $15 \%$ and $20 \%$ at day 8 and day 21 , respectively. Open and closed columns represent the data at day 8 ( $n=5$ in each group) and day 21 ( $n=3$ in each group), respectively. Data expressed as the mean \pm standard error of the mean. ${ }^{\star} P<0.05$ and ${ }^{\star \star} P<0.01$, compared with contralateral knees.

\section{Discussion}

In the present study we have shown that daily injections of AM into the knee joint spaces of rabbits with AIA ameliorated the inflammatory response associated with the disease. Treatment with $A M$ reduced joint swelling, and reduced the expression of TNF $\alpha$ mRNA, edematous changes and the number of infiltrating inflammatory cells in the synovial tissue. To the best of our knowledge, this is the first report to show the effects of daily intra-articular injections of AM in rabbits with AIA.
We observed that AM suppressed joint swelling (Figures 2 and 3). Histologically, AM treatment reduced edematous changes and increased the ratio of connective tissue in the infrapatellar fat pad (Figures 7, 8 and 9). A previous study showed that TNF $\alpha$ induced cytoskeletal reorganization of endothelial cells and increased endothelial permeability by stimulating TNF receptors 1 and 2 [17]. In addition, TNF $\alpha$ facilitates the ability of VEGF to promote excessive vascular permeability [18]. TNF $\alpha$ also suppresses the expression of matrix genes and the induction of connective tissue growth factor by TGF $\beta$ during the wound healing response [19]. TNF $\alpha$ therefore aggravates edematous changes and suppresses the fibrotic response of the tissue. Moreover, AM was shown to reduce endothelial hyperpermeability induced by hydrogen peroxide, thrombin, and Escherichia coli hemolysin [20].

Two research groups reported recently that $A M$ signaling deficiency in mice resulted in midgestation death and massive edema. The cause of this edema was shown to be a result of fragility and hyperpermeability of blood vessels in one group and to be a failure of lymphatic vessel growth in the other $[21,22]$. The evidence from these studies suggests that AM plays an important role in preventing edema. From these observations, we speculate that AM not only suppresses the production of TNF $\alpha$, but also directly and indirectly inhibits edematous changes in the inflamed joint.

Although RA is a chronic and systemic inflammatory disorder of unknown etiology, TNF $\alpha$ has been shown to play a central role in the pathogenesis of RA $[1,2,23]$. TNF $\alpha$ stimulates the proliferation of synovial cells and the production of matrix metalloproteinases by chondrocytes and synovial cells, and induces the release of other proinflammatory cytokines, leading to joint destruction $[23,24]$. We have shown that daily injections of AM into the knee joint spaces of rabbits with AIA suppressed the expression of TNF $\alpha$ mRNA in the synovial tissue in a dose-dependent manner (Figure 10a). It has been

Figure 8
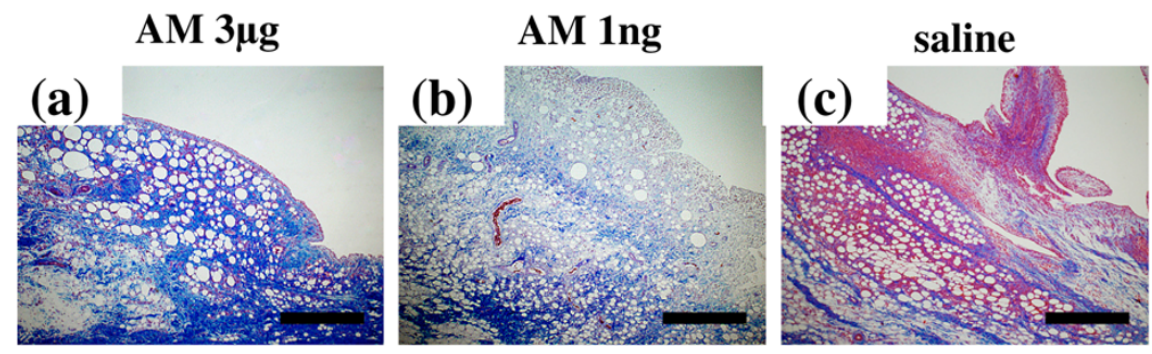

Histological analysis of infrapatellar fat-pad sections stained with Mallory - Azan from rabbits with antigen-induced arthritis. Rabbits with antigen-induced arthritis (AIA) were treated with daily injections of adrenomedullin (AM) or saline (control) into the knee joint spaces for 20 days. The infrapatellar fat pads were harvested from rabbit knees 21 days after arthritis induction. The tissues were sectioned longitudinally perpendicular to the patella ligament in the middle of the tissue, and were stained with Mallory - Azan. (a) AIA rabbit knee was treated with daily intra-articular injections of $3 \mu \mathrm{g} \mathrm{AM}$ for 20 days. (b) AIA rabbit knee was treated with daily intra-articular injections of $1 \mathrm{ng}$ AM for 20 days. (c) The contralateral knee of (a) was treated with daily intra-articular injections of saline for 20 days. Photographs taken at $\times 40$ magnification. Bar $=500 \mu \mathrm{m}$. 
Figure 9

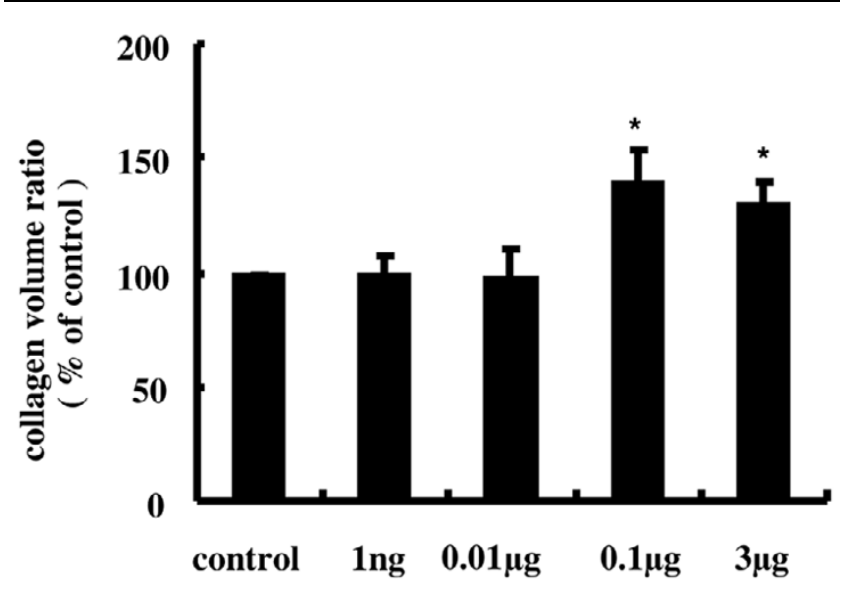

Quantitative evaluation of collagen volume in the infrapatellar fat pad. To measure the collagen volume, the sections with Mallory - Azan stain were projected onto a color imaging analysis system. In each section, 10 separate sites were analyzed and the collagen volume fraction was obtained by calculating the mean ratio of connective tissue to the total tissue area. The collagen volume ratio was increased in adrenomedullin (AM)-treated knees by $39 \%$ and $31 \%$ at $0.1 \mu \mathrm{g}$ and $3 \mu \mathrm{g} \mathrm{AM}$, respectively. Data expressed as the mean \pm standard error of the mean. ${ }^{*} P<0.05$, compared with contralateral knees.

reported that AM suppressed the secretion of TNF $\alpha$ from lipopolysaccharide-stimulated RAW 264.7 macrophages and NR8383 macrophages [4-6]. Because the major source of TNF $\alpha$ in inflamed synovial tissue of RA is due to macrophages [25], it is plausible that AM suppresses the production of TNF $\alpha$ from activated macrophages in inflamed synovial tissue.

On the contrary, we found that AM increased IL-6 mRNA expression in the synovial tissue (Figure 10b). Our results agree with previous findings on the effects of AM on IL-6 production. AM is reported to augment the production of IL- 6 from NR8383 cells and Swiss 3T3 fibroblast cells stimulated with lipopolysaccharide or cytokines $[4,26]$. Several observations support the concept that IL- 6 is an anti-inflammatory cytokine [27]. IL-6 has been shown to have a suppressive effect on TNF $\alpha$ and IL-1 $\beta$ production in peripheral blood mononuclear cells and exerts its anti-inflammatory effects in hepatitis by reducing the production of TNF $[28,29]$. Our results therefore lead us to speculate that the mechanism involved in the antiinflammatory effects of AM is related to suppression of TNF $\alpha$ in inflamed synovial tissue directly or through IL-6 production.

Overproduction of IL-6 has been observed and is known to cause unfavorable clinical symptoms in immune-inflammatory diseases such as RA. Overproduction of IL-6 induces the production of rheumatoid factors and increases antibody levels, the platelet count, C-reactive protein levels, and serum amyloid A protein levels in RA [30]. Treatment with a humanized anti-IL-6 receptor antibody has also been shown to reduce RA disease activity $[30,31]$. The effect of AM on IL-6 production might therefore be an undesirable adverse effect in RA ther- apy. Plasma AM levels have been reported to increase with RA disease activity and in the acute or flare phase of myocardial infarction and sepsis $[10,11,32,33]$. Recent studies have shown that $\mathrm{AM}$ administration in the acute phase reaction of several disease models produced significant protective effects in organs against inflammation and oxidative stress [34-36]. Miyashita and colleagues reported that AM administration to prevent ischemic brain damage in mice less than 72 hours after the ischemic event showed significant therapeutic effects, whereas AM administration more than 72 hours after stroke onset produced no significant therapeutic effects [37].

From these observations and our study findings, we speculate that the effects of AM may be dependent on the tissue environment and the disease state; that is, the role and effects of $A M$ in inflammation may change during the inflammatory process. AM acts as a strong anti-inflammatory agent in the acute or flare phase of inflammation, but in the chronic phase of inflammation AM may act not only as an anti-inflammatory agent but also as a proinflammatory agent. It is therefore important to consider the time of administration, the route of administration and the dosage schedule of AM in the treatment of RA.

\section{Conclusion}

In the present study, the effects of daily intra-articular injections of AM into the knees of rabbits with AIA were examined. The results suggest that $\mathrm{AM}$ suppresses the inflammatory response in inflamed joints by inhibiting the expression of TNF $\alpha$ mRNA and increasing IL-6 mRNA level.

Although AM may have anti-inflammatory properties, the effect of AM on IL- 6 production in inflamed synovial tissue might be an undesirable adverse effect in RA therapy. Further research is necessary to investigate the drug effects, the time of administration and the dosage schedules of intra-articular injection of $A M$ in the treatment of RA.

\section{Competing interests}

The authors declare that they have no competing interests.

\section{Authors' contributions}

$\mathrm{TO}$ and KM had full access to all of the study data and take full responsibility for the integrity of the data and the accuracy of the data analysis. $\mathrm{EC}$ and $\mathrm{HH}$ conceived the study, and participated in the study design. TS helped to develop the animal model and draft the manuscript. TF helped to carry out realtime PCR and perform statistical analyses. YA performed the histological evaluation. KK measured the level of AM in plasma and participated in the study design. 
(a)

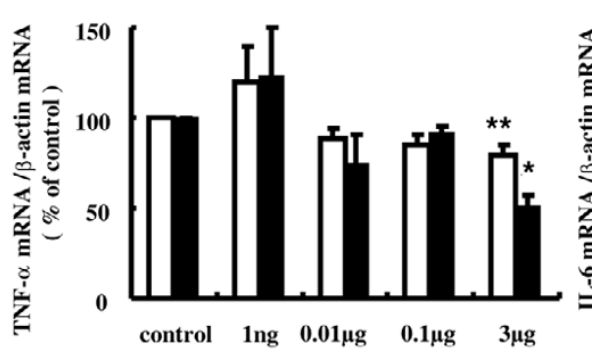

(c)

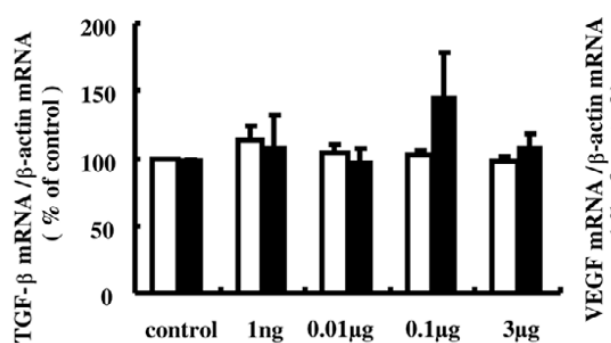

(b)
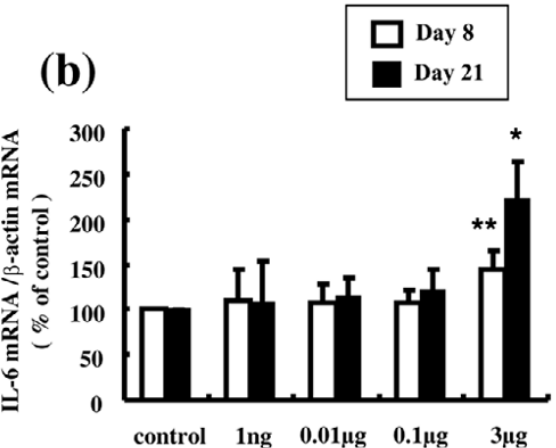

(d)

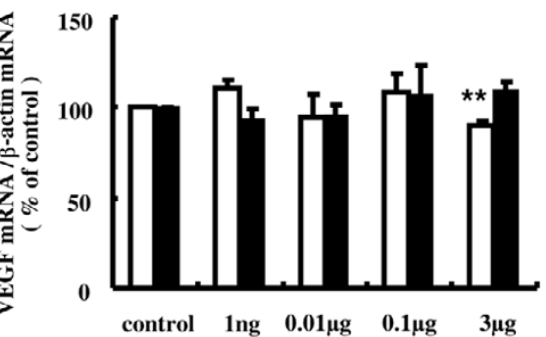

Effect of adrenomedullin on cytokine mRNA expression linked to antigen-induced arthritis. Expression levels of TNF $\alpha$, IL-6, transforming growth factor beta (TGF $\beta$ ), and vascular endothelial growth factor (VEGF) mRNA in the infrapatellar fat pads were determined by real-time quantitative PCR. (a) Adrenomedullin (AM) treatment reduced TNF $\alpha$ mRNA expression in a dose-dependent manner. Daily intra-articular injections of $3 \mu \mathrm{g}$ AM significantly suppressed the TNF $\alpha$ mRNA level by $21 \%$ and $49 \%$ at day 8 and day 21 , respectively. (b) AM increased IL-6 mRNA expression in a dose-dependent manner. Daily intra-articular injections of $3 \mu \mathrm{g} \mathrm{AM}$ significantly increased the IL-6 mRNA level by $45 \%$ and $121 \%$ at day 8 and day 21 , respectively. (c) AM treatment did not alter the TGF $\beta$ mRNA level. (d) Although the VEGF mRNA level was suppressed by $10 \%$ at $3 \mu \mathrm{g}$ AM on day 8 , a dose-dependent effect of AM on VEGF mRNA expression was not observed. Open and closed columns represent the data at day 8 ( $n=5$ in each group) and day 21 ( $n=3$ in each group), respectively. Data expressed as the mean \pm standard error of the mean. ${ }^{*} P<0.05$ and ${ }^{* *} P<0.01$, compared with contralateral knees

\section{Acknowledgements}

The authors would like to thank Dr Atsushi Yamashita for his helpful discussion, Ms Kyoko Ohashi for technical support in the western blot analysis, and Ms Mariko Tokashiki for technical support in measurement of the plasma AM concentration. The present study was supported by Grants-in Aid for Scientific Research from the Ministry of Education in Japan (No. 16591498).

\section{References}

1. Moreland LW, Baumgartner SW, Schiff MH, Tindall EA, Fleischmann RM, Weaver AL, Ettlinger RE, Cohen S, Koopman WJ, Mohler K, Widmer MB, Blosch CM: Treatment of rheumatoid arthritis with a recombinant human tumor necrosis factor receptor (p75)-Fc fusion protein. N Engl J Med 1997, 337:141-147.

2. Elliott MJ, Maini RN, Feldmann M, Long-Fox A, Charles $P$, Katsikis P, Brennan FM, Walker J, Bijl H, Ghrayeb J, Woody JN: Treatment of rheumatoid arthritis with chimeric monoclonal antibodies to tumor necrosis factor alpha. Arthritis Rheum 1993, 36:1681-1690.

3. Kitamura K, Kangawa K, Kawamoto M, Ichiki Y, Nakamura S, Matsuo $\mathrm{H}$, Eto T: Adrenomedullin: a novel hypotensive peptide isolated from human pheochromocytoma. Biochem Biophys Res Commun 1993, 192:553-560.

4. Wong LY, Cheung BM, Li YY, Tang F: Adrenomedullin is both proinflammatory and antiinflammatory: its effects on gene expression and secretion of cytokines and macrophage migration inhibitory factor in NR8383 macrophage cell line. Endocrinology 2005, 146:1321-1327.

5. Kubo A, Minamino N, Isumi $Y$, Katafuchi T, Kangawa K, Dohi K, Matsuo $\mathrm{H}$ : Production of adrenomedullin in macrophage cell line and peritoneal macrophage. J Biol Chem 1998, 273:16730-16738.

6. Wu R, Zhou M, Wang P: Adrenomedullin and adrenomedullin binding protein-1 downregulate TNF- $\alpha$ in macrophage cell line and rat Kupffer cells. Regul Pept 2003, 112:19-26.

7. Gonzalez-Rey E, Fernandez-Martin A, Chorny A, Delgado M: Therapeutic effect of urocortin and adrenomedullin in a murine model of Crohn's disease. Gut 2006, 55:824-832.

8. Ashizuka S, Ishikawa N, Kato J, Yamaga J, Inatsu H, Eto T, Kitamura $\mathrm{K}$ : Effect of adrenomedullin administration on acetic acidinduced colitis in rats. Peptides 2005, 26:2610-2615.

9. Gonzalez-Rey E, Chorny A, O'Valle F, Delgado M: Adrenomedullin protects from experimental arthritis by down-regulating inflammation and Th1 response and inducing regulatory $T$ cells. Am J Pathol 2007, 170:263-271.

10. Chosa E, Hamada H, Kitamura K, Eto T, Tajima N: Increased plasma and joint tissue adrenomedullin concentrations in patients with rheumatoid arthritis compared to those with osteoarthritis. J Rheumato/ 2003, 30:2553-2556.

11. Yudoh $\mathrm{K}$, Matsuno $\mathrm{H}$, Kimura T: Plasma adrenomedullin in rheumatoid arthritis compared with other rheumatic diseases. Arthritis Rheum 1999, 42:1297-1298.

12. Dumonde DC, Glynn LE: The production of arthritis in rabbits by an immunological reaction to fibrin. $\mathrm{Br} J$ Exp Pathol 1962, 43:373-383. 
13. Consden R, Doble A, Glynn LE, Nind AP: Production of a chronic arthritis with ovalbumin. Its retention in the rabbit knee joint. Ann Rheum Dis 1971, 30:307-315.

14. Kita T, Kitamura K, Hashida S, Morishita K, Eto T: Plasma adrenomedullin is closely correlated with pulse wave velocity in middle-aged and elderly patients. Hypertens Res 2003, 26:887-893.

15. Reno C, Boykiw R, Martinez ML, Hart DA: Temporal alterations in mRNA levels for proteinases and inhibitors and their potential regulators in the healing medial collateral ligament. Biochem Biophys Res Commun 1998, 252:757-763.

16. Zagariya A, Bhat R, Navale S, Chari G, Vidyasagar D: Inhibition of meconium-induced cytokine expression and cell apoptosis by pretreatment with captopril. Pediatrics 2006, 117:1722-1727.

17. Ferrero E, Zocchi MR, Magni E, Panzeri MC, Curnis F, Rugarli C, Ferrero ME, Corti A: Roles of tumor necrosis factor p55 and p75 receptors in TNF- $\alpha$-induced vascular permeability. Am J Physiol Cell Physiol 2001, 281:c1173-c1179.

18. Clauss M, Sunderkötter $C$, Sveinbjörnsson B, Hippenstiel S, Willuweit A, Marino M, Haas E, Seljelid R, Scheurich P, Suttorp N, Grell M, Risau W: A permissive role for tumor necrosis factor in vascular endothelial growth factor-induced vascular permeability. Blood 2001, 97:1321-1329.

19. Leask $A$, Abraham DJ: TGF- $\beta$ signaling and the fibrotic response. FASEB J 2004, 18:816-827.

20. Hippenstiel S, Witzenrath M, Schmeck B, Hocke A, Krisp M, Krüll M, Seybold J, Seeger W, Rascher W, Schütte H, Suttorp N: Adrenomedullin reduces endothelial hyperpermeability. Circ Res 2002, 91:618-625.

21. Ichikawa-Shindo $Y$, Sakurai $T$, Kamiyoshi $A$, Kawate $H$, linuma $N$, Yoshizawa T, Koyama T, Fukuchi J, limuro S, Moriyama N, Kawakami H, Murata T, Kangawa K, Nagai R, Shindo T: The GPCR modulator protein RAMP2 is essential for angiogenesis and vascular integrity. J Clin Invest 2008, 118:29-39.

22. Fritz-Six KL, Dunworth WP, Li M, Caron KM: Adrenomedullin signaling is necessary for murine lymphatic vascular development. J Clin Invest 2008, 118:40-50.

23. Arend WP, Dayer JM: Inhibition of the production and effects of interleukin-1 and tumor necrosis factor alpha in rheumatoid arthritis. Arthritis Rheum 1995, 38:151-160.

24. Nishimoto N, Ito A, Ono M, Tagoh H, Matsumoto T, Tomita T, Ochi T, Yoshizaki K: IL-6 inhibits the proliferation of fibroblastic synovial cells from rheumatoid arthritis patients in the presence of soluble IL-6 receptor. Int Immuno/ 2000, 12:187-193.

25. Chu CQ, Field M, Feldmann M, Maini RN: Localization of tumor necrosis factor alpha in synovial tissues and at the cartilage-pannus junction in patients with rheumatoid arthritis. Arthritis Rheum 1991, 34:1125-1132.

26. Isumi Y, Minamino N, Kubo A, Nishimoto N, Yoshizaki K, Yoshioka M, Kangawa K, Matsuo H: Adrenomedullin stimulates interleukin-6 production in Swiss 3T3 cells. Biochem Biophys Res Commun 1998, 244:325-331.

27. Tilg H, Dinarello CA, Mier JW: IL-6 and APPs: anti-inflammatory and immunosuppressive mediators. Immunol Today 1997, 18:428-432.

28. Schindler R, Mancilla J, Endres S, Ghorbani R, Clark SC, Dinarello $\mathrm{CA}$ : Correlations and interactions in the production of interleukin-6 (IL-6), IL-1, and tumor necrosis factor (TNF) in human blood mononuclear cells: IL-6 suppresses IL-1 and TNF. Blood 1990, 75:40-47.

29. Mizuhara H, O'Neill E, Seki N, Ogawa T, Kusunoki C, Otsuka K, Satoh S, Niwa M, Senoh H, Fujiwara H: T cell activation-associated hepatic injury: mediation by tumor necrosis factors and protection by interleukin 6. J Exp Med 1994, 179:1529-1537.

30. Nishimoto $\mathrm{N}$, Kishimoto T, Yoshizaki K: Anti-interleukin 6 receptor antibody treatment in rheumatic disease. Ann Rheum Dis 2000, 59(Suppl 1):i21-i27.

31. Nishimoto N, Yoshizaki K, Miyasaka N, Yamamoto K, Kawai S, Takeuchi T, Hashimoto J, Azuma J, Kishimoto T: Treatment of rheumatoid arthritis with humanized anti-interleukin- 6 receptor antibody: a multicenter, double-blind, placebo-controlled trial. Arthritis Rheum 2004, 50:1761-1769.

32. Kobayashi K, Kitamura $\mathrm{K}$, Hirayama N, Date $\mathrm{H}$, Kashiwagi $T$, Ikushima I, Hanada Y, Nagatomo Y, Takenaga M, Ishikawa T, Imamura T, Koiwaya $Y$, Eto $T$ : Increased plasma adrenomedullin in acute myocardial infarction. Am Heart J 1996, 131:676-680.
33. Hirata Y, Mitaka C, Sato K, Nagura T, Tsunoda Y, Amaha K, Marumo F: Increased circulating adrenomedullin, a nove vasodilatory peptide, in sepsis. J Clin Endocrinol Metab 1996, 81:1449-1453.

34. Kawai J, Ando K, Tojo A, Shimosawa T, Takahashi K, Onozato ML, Yamasaki M, Ogita T, Nakaoka T, Fujita T: Endogenous adrenomedullin protects against vascular response to injury in mice. Circulation 2004, 109:1147-1153.

35. Nakamura R, Kato J, Kitamura K, Onitsuka H, Imamura T, Cao Y, Marutsuka K, Asada Y, Kangawa K, Eto T: Adrenomedullin administration immediately after myocardial infarction ameliorates progression of heart failure in rats. Circulation 2004, 110:426-431.

36. Yang S, Zhou M, Fowler DE, Wang P: Mechanisms of the beneficial effect of adrenomedullin and adrenomedullin-binding protein-1 in sepsis: down-regulation of proinflammatory cytokines. Crit Care Med 2002, 30:2729-2735.

37. Miyashita $\mathrm{K}$, Itoh $\mathrm{H}$, Arai $\mathrm{H}$, Suganami T, Sawada N, Fukunaga $Y$, Sone M, Yamahara K, Yurugi-Kobayashi T, Park K, Oyamada N, Sawada N, Taura D, Tsujimoto H, Chao TH, Tamura N, Mukoyama $\mathrm{M}$, Nakao $\mathrm{K}$ : The neuroprotective and vasculo-neuro-regenerative roles of adrenomedullin in ischemic brain and its therapeutic potential. Endocrinology 2006, 147:1642-1653. 